https://journal-computing.org/index.php/journal-cisa/index

\title{
Perancangan Sistem Informasi Indeks KAMI
}

\author{
Muhammad Burhanur Rizki, Ahmad Syazili \\ Fakultas Ilmu Komputer, Universitas Bina Dama \\ Email: burhanerik550@gamil.com, syazili@binadarma.ac.id
}

\begin{abstract}
ABSTRAK
Universitas Bina Darma memiliki aset teknologi informasi, untuk mengelola aset teknologi informasi Universitas Bina Darma menggunakan standar Indeks KAMI, Universitas Bina Darma pernah mengikuti assessment Indeks KAMI oleh BSSN (Badan Siber dan Sandi Negara) dengan hasil yang belum memuaskan. Karena Universitas Bina Darma belum mempersiapkan dokumen-dokumen Indeks KAMI dengan matang, serta belum adanya sistem untuk mengelola dokumen tersebut. Untuk mengelola dokumen Indeks KAMI Universitas Bina Darma masih menggunakan cara manual dan belum menggunakan sistem, sehingga pengelolaan dokumen Indeks KAMI kurang efektif. Dari uraian diatas Universitas Bina Darma membutuhkan sebuah sistem yang dapat mengelola dokumen yang nantinya memudahkan Universitas Bina Darma mengetahui tingkat kesiapan dan kematangan keamanan informasi.
\end{abstract}

Kata Kunci : Website Indeks KAMI.

\section{PENDAHULUAN}

Seiring dengan perkembangan zaman, kemajuan teknolgi informasi saat ini semakin pesat. Teknologi informasi merupakan salah satu aset yang sangat berharga baik itu bagi perusahaan atau instansi yang telah menerapkan teknologi informasi dalam proses bisnisnya. Teknologi informasi di perusahaan atau instansi dapat meningkatkan efektifitas dan efisiensi dalam perusahaan atau instansi yang menerapkan dan mengelola teknologi informasi. Penerapan dan pengelolaan teknologi informasi yang baik akan memberikan jaminan terhadap keamanan aset teknologi informasi. Aset teknologi informasi yang dimaksud mencakup informasi, software, hardware, sarana pendukung dan sumber daya manusia yang ada pada perusahaan atau instansi itu sendiri. Salah satu instansi swasta yang telah menerapkan teknologi informasi dalam proses bisnisnya yaitu Universitas Bina Darma.

Universitas Bina Darma merupakan instansi yang begerak pada bidang pendidikan, yang berdiri pada tanggal 28 Desember 1993 yang beralamat, Jalan Jend A.Yani No. 12 Seberang Ulu Kota Palembang. Universitas Bina 


\section{Journal of Computer and Information Systems Ampera}

Vol. 2, No. 3, September 2021 e-ISSN: 2775-2496

https://journal-computing.org/index.php/journal-cisa/index

Darma bagian Direktorat Sistem dan Teknologi Informasi (DSTI) yang dikhususkan untuk menangani permasalahan teknologi informasi dan sistem informasi yang dimiliki Universitas Bina Darma. Semua kegiatan yang berkaitan dengan teknologi, sistem serta keamanan informasi dipusatkan dan dikembangkan di DSTI Universitas Bina Darma. Keamanan Informasi merupakan aset yang sangat penting bagi Universitas Bina Darma.

Pengelolaan informasi yang baik akan menjadikan Universitas Bina Darma memiliki kemampuan manajerial yang baik serta menghasilkan informasi yang baik. Mengingat arti pentingnya suatu informasi, maka Universitas Bina Darma perlu menjaga dan mengelola keamanan informasi di lingkungannya. Salah cara untuk menjaga dan mengelola keamanan aset teknologi informasi yaitu dengan mengukur tingkat kematangan keamanan informasi. Dalam mengukur tingkat kematangan keamanan informasi Universitas Bina Darma menggunakan aplikasi Indeks KAMI yang merujuk pada ISO/IEC 27001:2013(Basyarahil, n.d.-a).

Menurut https://bssn.go.id/indeks-kami/ Indeks Keamanan Informasi (KAMI) merupakan aplikasi yang digunakan sebagai alat bantu untuk melakukan asesmen dan evaluasi tingkat kesiapan (Kelengkapan dan Kematangan) penerapan keamanan informasi berdasarkan kriteria SNI ISO/IEC 27001, yaitu Tata Kelola, Pengelolaan Risiko, Kerangka Kerja, Pengelolaan Aset, Aspek Teknologi dengan suplemen, Pengamanan Keterlibatan Pihak Ketiga Penyedia Layanan, Pengamanan Layanan Infrastruktur Awan dan Perlindungan Data Pribadi. Indeks KAMI tidak ditujukan untuk menganalisis kelayakan atau efektivitas bentuk pengamanan yang ada, melainkan sebagai perangkat untuk memberikan gambaran kondisi kesiapan kerangka kerja keamanan informasi. Pada Universitas Bina Darma proses evaluasi tingkat kematangan dan kesiapan informasi masih dilakukan secara manual dimana proses evaluasi dilakukan oleh tim dari BSSN (Badan Siber dan Sandi Negara). Tim BSSN melakukan assessment (Penilaian) dengan memberikan pertanyaan yang ada pada aplikasi Indeks Kami versi MS.Excel yang mana penilaian dilakukan secara langsung atau virtual, kemudian hasil dari penilaian akan di hitung menggunakan aplikasi Indeks KAMI. 


\section{Journal of Computer and Information Systems Ampera}

Vol. 2, No. 3, September 2021 e-ISSN: 2775-2496

https://journal-computing.org/index.php/journal-cisa/index

\section{METODOLOGI PENELITIAN}

\subsection{Kerangka Kerja}

Uraian kerangka kerja dalam penelitian ini adalah uraian secara rinci terhadap masing-masing kerangka kerja yang telah di susun agar penelitian yang di lakukan dapat terlaksana secara terstruktur dan jelas. Kerabgka kerja dalam penelitian ini sebagai berikut.

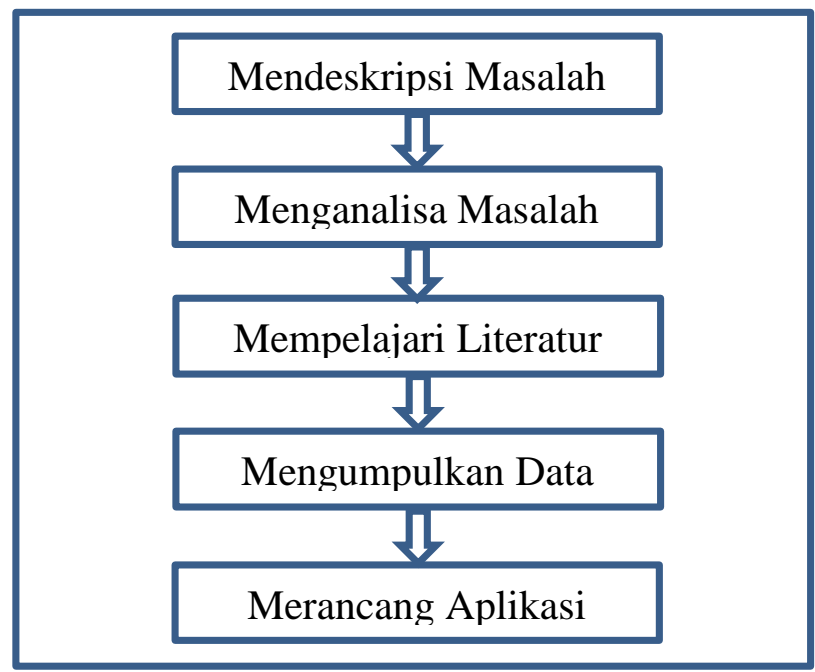

\subsubsection{Mendeskripsikan Masalah}

Mendeskripsikan masalah adalah melakukan perumusan terhadap masalah-masalah yang telah diidentifikasi dari suatu sistem. Merumuskan adalah mengkonsep, menformulakan, mempolakan dan memperjelaskan suatu hal yang telah diidentifikasi sebelumnya. Merumuskan masalah sangat diperlukan dalam suatu penelitian agar penelitian tersebut dapat menghasilkan kesimpulan yang terkonsep, terformula, terpola dan jelas. Dalam penelitian ini rumusan masalah yang dilakukan adalah bagaimana merancang sebuah sisitem informasi Indeks KAMI pada Universitas Bina Darma. 
Journal of Computer and Information Systems Ampera

Vol. 2, No. 3, September 2021 e-ISSN: 2775-2496

https://journal-computing.org/index.php/journal-cisa/index

\subsubsection{Menganalisa Masalah}

Menganalisa masalah merupakan langkah analisis masalah untuk dapat memahami masalah yang telah ditentukan ruang lingkup atau batasannya. Dengan menganalisa masalah yang telah ditentukan tersebut, maka diharapkan masalah dapat dipahami dengan baik. Masalah yang terjadi pada Indeks KAMI adalah sistem yang masih bersifat manual sehingga sering terjadi human error.

\subsubsection{Mempelajari Literatur}

Mempelajari Literatur atau studi literature adalah tindakan yang dilakukan untuk mempelajari secara ilmiah dan teoritis terhadap masalahmasalah yang telah dibatasi sebelumnya yang bersumber dari buku, jurnal, karya tulis ilmiah, artikel, tesis dan sebagainya sangat diperlukan agar penelitian yang dilakukan berpijak pada landasan teori yang jelas dan benar yang telah dikemukakan oleh parah ahli sebelumnya. Dengan melakukan studi literature maka penelitian yang dilakukan tidak mengarang dan mengada-ada sehingga dapat diterima di dunia ilmu pengetahian dan masyarakat umum.

\subsubsection{Mengumpulkan Data}

Mengumpulkan data dilakukan untuk mengumpulkan semua data-data yang diperlukan dalam penelitian. Teknik yang dilakukan dalam mengumpulkan data dalam penelitian ini adalah dengan teknik observasi. Teknik observasi adalah teknik pengamatan secara langsung ke lapangan dengan mencatat data-data yang diperlukan. Selain teknik observasi, penulis juga melakukan pengumpulan data dan informasi dengan mengadakan tanya jawab secara langsung, diskusi dan konsultasi kepada pihak-pihak yang berkaitan dengan penelitian.

\subsubsection{Merancang Aplikasi}

Pada tahap ini, penulis merancangan aplikasi yang dapat memberikan manfaat terhadap Universitas Bina Darma. Rancangan tersebut dapat dilakukan dengan cara menggambarkan Diagran Konteks (Context Diagram), DFD (Data Flow Diagram), dan ERD (Entity Relationship Diagram). 


\section{Journal of Computer and Information Systems Ampera}

Vol. 2, No. 3, September 2021 e-ISSN: 2775-2496

https://journal-computing.org/index.php/journal-cisa/index

\subsection{Metode Pengumpulan Data}

Pengumpulan data dan informasi yang diperlukan dalam penelitian ini dengan menggunakan cara sebagai berikut:

1. Observasi

Dalam penelitian ini dilakukan dengan cara melakukan pengamatan secara langsung di Universitas Bina Darma dengan tujuan untuk mencari informasi dan mengetahui informasi data yang diperlukan dalam melakukan penelitian.

2. Wawancara

Wawancara merupakan pengumpulan data yang dilakukan dengan bertanya langsung kepada bagian Direktorat Sistem Teknologi dan Informasi (DSTI) untuk memberikan informasi yang berhubungan dengan data yang dibutuhkan oleh penulis.

3. Studi Pustaka

Studi pustaka diperoleh dengan cara browsing melalui internet, mempelajari buku dan jurnal-jurnal yang behubungan dengan topik penelitian untuk dapat digunakan sebagai acuan untuk melakukan penelitian.

\subsection{Metode Pengembangan Sistem}

Dalam perancangan sistem ini penulis menggunakan metode pengembangan sistem Web Engineering, dalam penelitian ini langkah penerapan metode web engineering meliputi 5 tahap yaitu:

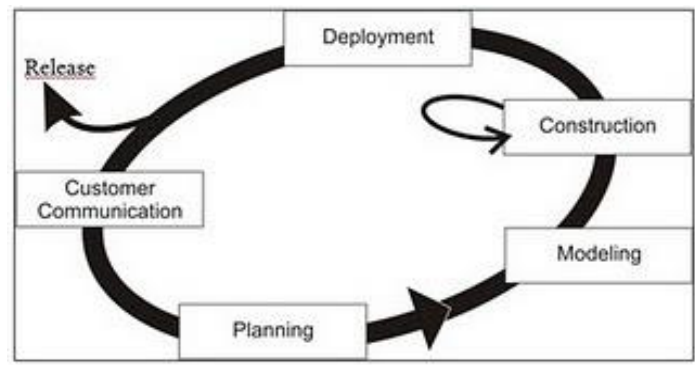

Gambar 2.3.1 Metode Web Engineering 


\section{Journal of Computer and Information Systems Ampera}

Vol. 2, No. 3, September 2021 e-ISSN: 2775-2496

https://journal-computing.org/index.php/journal-cisa/index

\subsubsection{Customer Communication}

Pada tahapan ini penulis telah berkomunikasi dengan user atau pengguna sistem yang akan di bangun ini untuk mengetahui apa saja yang diinginkan oleh user dan apa saja kebutuhan user serta kebutuhan sistem yaitu dari sisi input dan output yang akan dihasilkan serta fasilitas apa saja yang harus ada pada sistem ini nantinya. Setelah diketahui apa saja kebutuhan user dan kebutuhan sistem, dengan melakukan wawancara pada stakeholders yang ada untuk mengetahui proses dan untuk melihat bagaimana proses itu terjadi.

\subsubsection{Planning}

Pada tahapan ini penulis harus merencanakan semua kebutuhan yang diperlukan dalam membangun sebuah sistem agar bejalan dengan lancar.

\subsubsection{Modeling}

Pada tahapan pemodelan (Modeling) ini, penulis melakukan analisa terhadap sistem yang berjalan, menganalisa kebutuhan sistem yang akan dikembangkan, serta membuat rancangan (design) struktur tabel basis data dan rancangan struktur menu serta tampilan halaman.

\subsubsection{Construction}

Suatu tahapan dalam menggunakan alat dan teknologi rekayasa web untuk membangun aplikasi web yang telah dirancang dengan menggunakan alat bantu perangkat lunak Macromedia Dreamweaver untuk mendesain halaman web dan bahasa pemrograman PHP serta database MySQL.

\subsubsection{Deployment}

Tahapan terakhir metode Web Engineering dalam bentuk pemasangan dan konfigurasi web. 


\section{Journal of Computer and Information Systems Ampera}

Vol. 2, No. 3, September 2021 e-ISSN: 2775-2496

https://journal-computing.org/index.php/journal-cisa/index

\section{Analisis Dan Perancangan}

\subsection{Analisis Sistem Yang Sedang Berjalan}

Menurut Jimmy L,Goal (2008:73), “Analisis sisttem adalah sebagai penguraian dari suatu sistem yang utuh kedalam bagian-bagian komponennya dengan maksud untuk mengidentifikasikan dan mengevaluasi permasalahan-permasalahan, yang terjadi dan kebutuhan yang diharapkan sehingga dapat diusulkan perbaikan-perbaikannya".

Langkah pertama dalam membuat sistem baru ini adalah mempelajari sistem yang sedang berjalan pada sebuah organisasi beserta dengan permasalahannya. Tujuannya adalah untuk mendapatkan gambaran secara jelas tentang bentuk permasalahan yang ada pada organisasi tersebut. Sistem yang berjalan masih bersifat manual, dimana Universitas Bina Darma belum memiliki sistem informasi pengelolaan dokumen Indeks KAMI. Analisis sistem yang sedang berjalan pada sistem informasi Indeks KAMI berbasis web pada Universitas Bina Darma, bertujuan untuk mengetahui lebih jelas bagaimana cara kerja sistem tersebut untuk dapat dijadikan sistem yang baru agara terkomputerisasi. Perancangan sistem yang sedang berjalan yang di lakukan berdasarkan urutan kejadian yang ada dan dari urutan tersebut di buat diagram aliran dukumen sebagai berikut.

1. Admin akan mengupload dokumen, mengedit dokumen dan menghapus dokumen.

2. Sedangka user hanya bisa mendownload dokumen.

\subsection{Analisis Sistem Yang Diusulkan}

Pada sistem ini dilakukan dengan membeli domain terlebih dahulu melalui jasa web hosting misalnya id web host yang menyediakan jasa pembelian domain beserta hostingannya dan setalah itu dapat membuat settingan server link domain dengan hostingannya.Analisis sistem yang diusulkan yang ada permasalahan pada sistem yang sedang berjalan maka diperlukan sistem baru yang dapat dikembangkan untuk itu Universitas Bina Darma membuat sebuah Sistem Informasi pengelolaan dokumen Indeks KAMI agar dapat membatu proses pengelolaan dan evaluasi dokumen yang ada di Universitas Bina Darma. Dalam tahap analisis ini penulis menguraikan sistem melalui website untuk Indeks KAMI adalah sebagai berikut: 


\section{Journal of Computer and Information Systems Ampera}

Vol. 2, No. 3, September 2021 e-ISSN: 2775-2496

https://journal-computing.org/index.php/journal-cisa/index

1. Untuk admin diharuskan login terlebih dahulu.

2. Kemudian admin menupload dokumen Indeks KAMI.

3. Admin juga bisa menghapus dokumen dan mengedit dokumen jika diperlukan.

4. Untuk mengunjungi sistus Indeks KAMI user harus mengakses website Indeks KAMI terlebih dahulu.

5. User dapat melihat dokumen-dokumen yang ada diwebsite Indeks KAMI.

6. Jika user ingin mendownload dokumen yang dipilih, klik tombol Unduh (Download).

\section{Desain Sistem}

\subsection{Use Case Diagram}

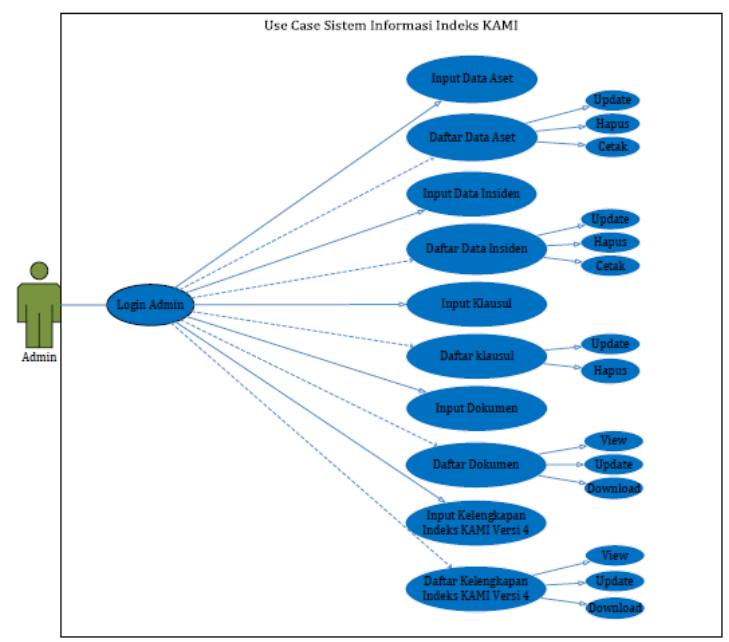

Gambar 4.1 Use Case Perncangan Sistem Informasi Indeks KAMI 


\section{Journal of Computer and Information Systems Ampera}

Vol. 2, No. 3, September 2021 e-ISSN: 2775-2496

https://journal-computing.org/index.php/journal-cisa/index

\subsection{Sequence Diagram}

\subsubsection{Sequence Diagram Klausul}

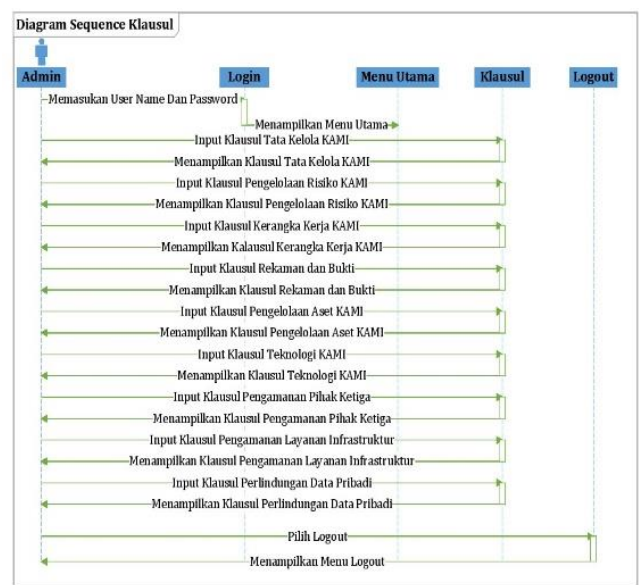

Gambar 4.2.1 Sequence Diagram Klausul Perncangan Sistem Informasi Indeks KAMI

\subsubsection{Sequence Diagram Dokumen}

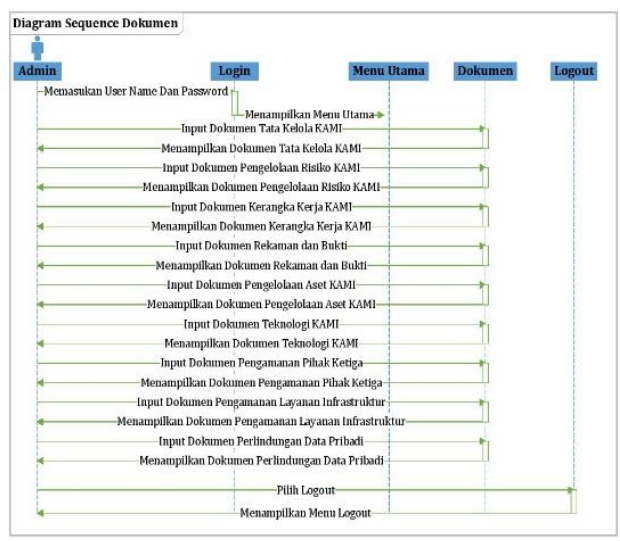

Gambar 4.2.2 Sequence Diagram Dokumen Perncangan Sistem Informasi Indeks KAMI 


\section{Journal of Computer and Information Systems Ampera}

Vol. 2, No. 3, September 2021 e-ISSN: 2775-2496

https://journal-computing.org/index.php/journal-cisa/index

\subsubsection{Sequence Diagram Aset}

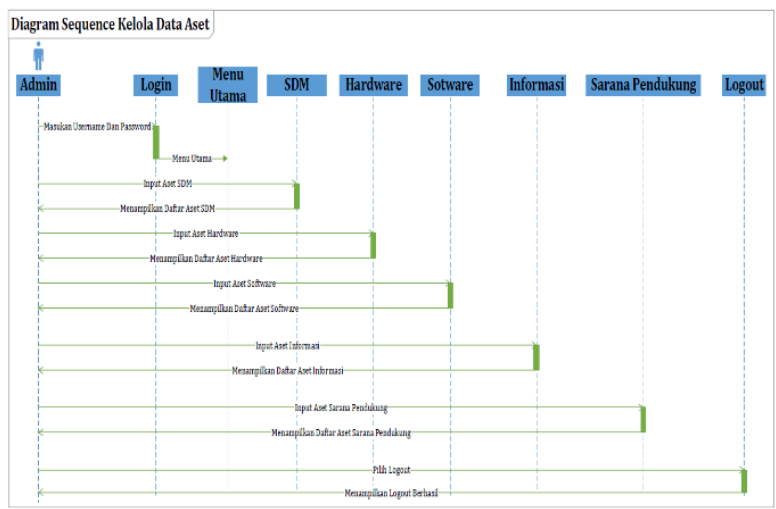

Gambar 4.2.3 Sequence Diagram Aset Perncangan Sistem Informasi Indeks KAMI

\subsubsection{Sequence Diagram Insiden}

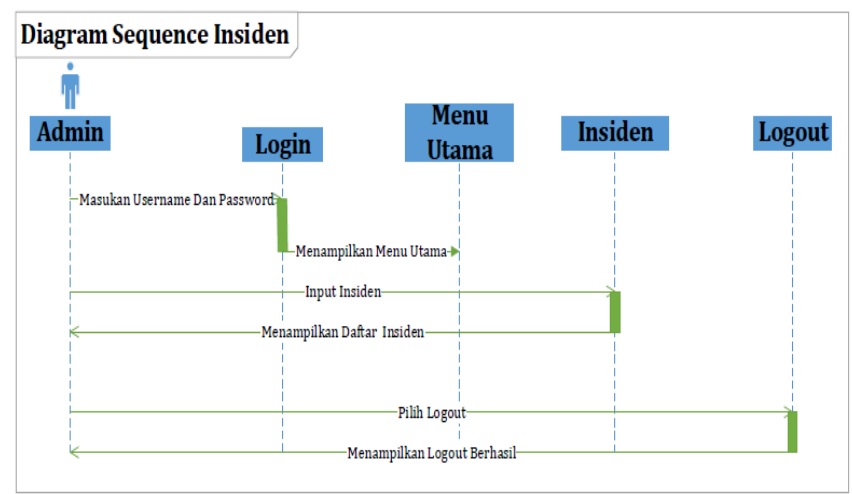

Gambar 4.2.4 Sequence Diagram Insiden Perncangan Sistem Informasi Indeks KAMI 


\section{Journal of Computer and Information Systems Ampera}

Vol. 2, No. 3, September 2021 e-ISSN: 2775-2496

https://journal-computing.org/index.php/journal-cisa/index

\subsubsection{Sequence Diagram Indeks KAMI}

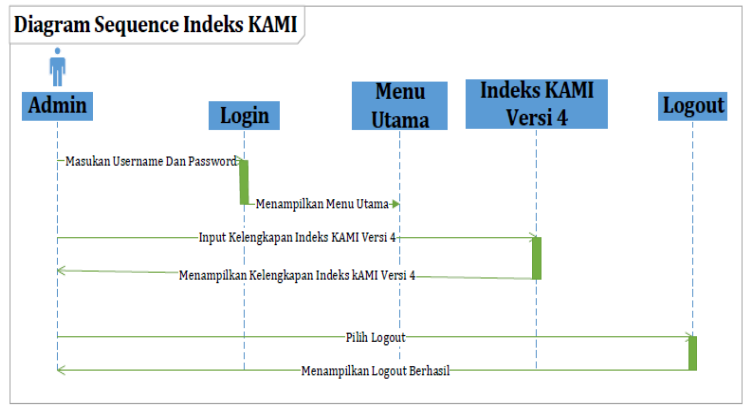

Gambar 4.2.5 Sequence Diagram Indeks KAMI Perncangan Sistem Informasi Indeks KAMI

\subsection{Activity Diagram}

\subsubsection{Activity Diagram Login}

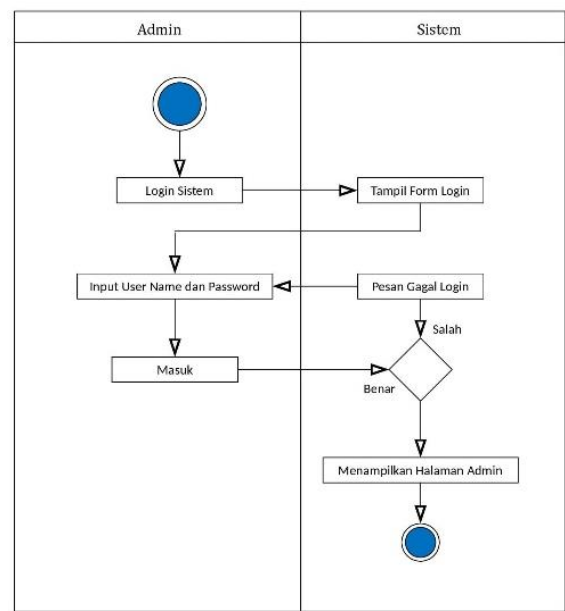

Gambar 4.3.1 Activity Diagram Login 


\section{Journal of Computer and Information Systems Ampera}

Vol. 2, No. 3, September 2021 e-ISSN: 2775-2496

https://journal-computing.org/index.php/journal-cisa/index

\subsubsection{Activity Diagram Klausul}

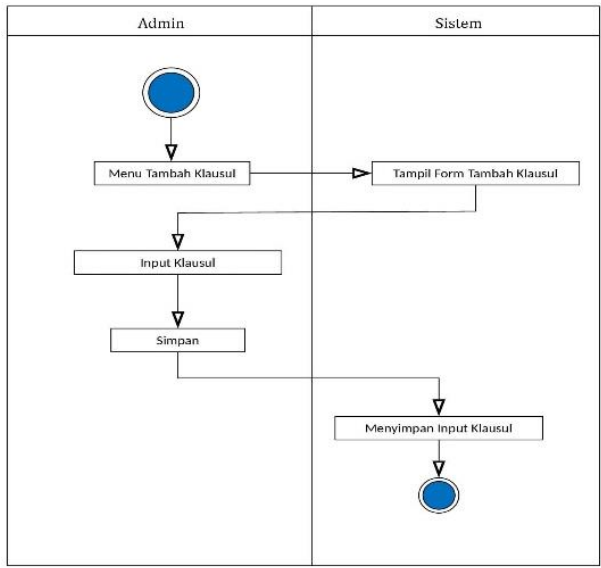

Gambar 4.3.2 Activity Diagram Klausul

\subsubsection{Activity Diagram Dokumen}

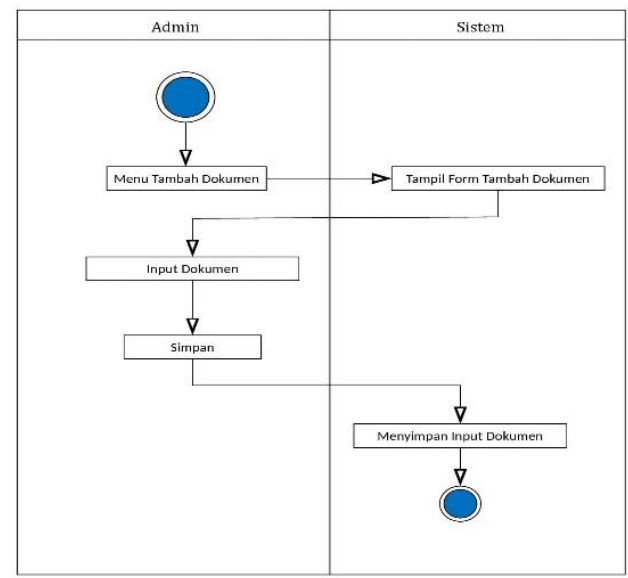

Gambar 4.3.3 Activity Diagram Dokumen 


\section{Journal of Computer and Information Systems Ampera}

Vol. 2, No. 3, September 2021 e-ISSN: 2775-2496

https://journal-computing.org/index.php/journal-cisa/index

\subsubsection{Activity Diagram Aset}

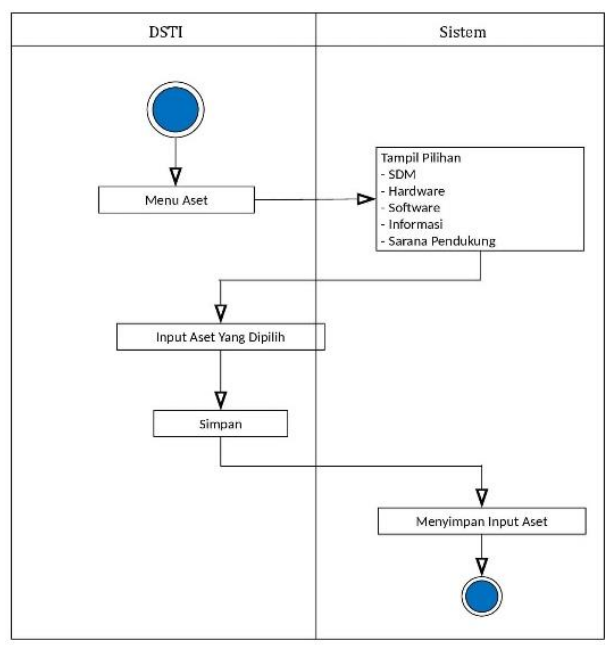

Gambar 4.3.4 Activity Diagram Aset

\subsubsection{Activity Diagram Insiden}

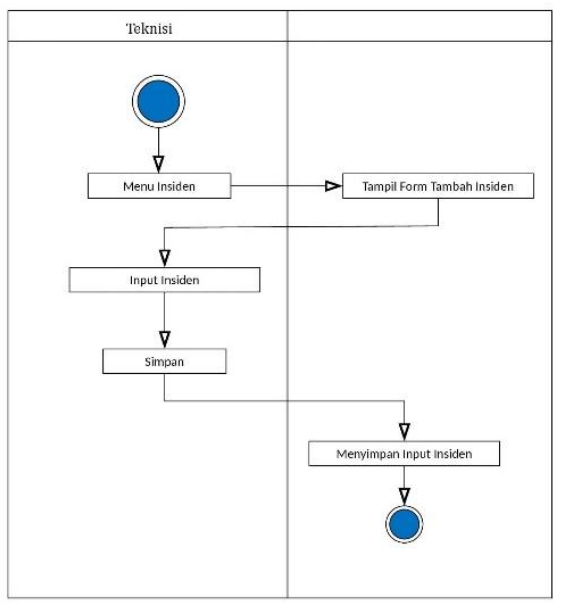

Gambar 4.3.5 Activity Diagram Insiden 


\section{Journal of Computer and Information Systems Ampera}

Vol. 2, No. 3, September 2021 e-ISSN: 2775-2496

https://journal-computing.org/index.php/journal-cisa/index

\subsection{User Interface Design}

\subsubsection{Rancangan Halaman Utama}

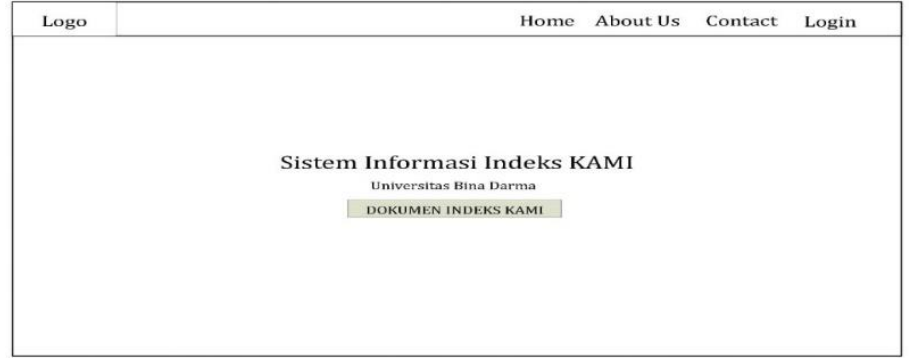

Gambar 4.4.1 Rancangan Halaman Utama

\subsubsection{Rancangan Halaman Lihat Dokumen}

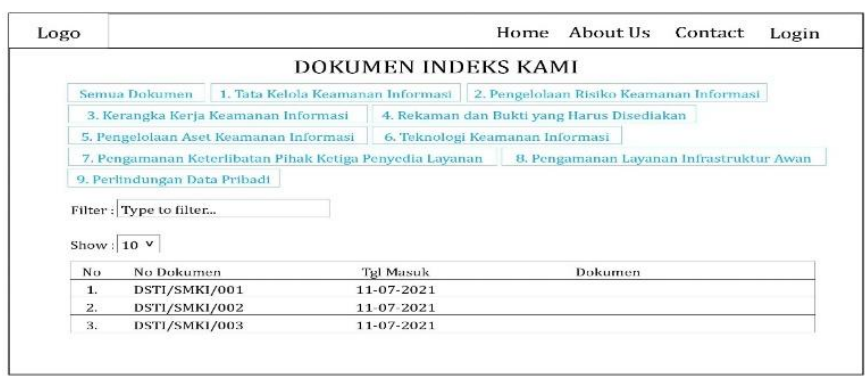

Gambar 4.4.2 Rancangan Halaman Lihat Dokumen

\subsubsection{Rancangan Halaman Contact}

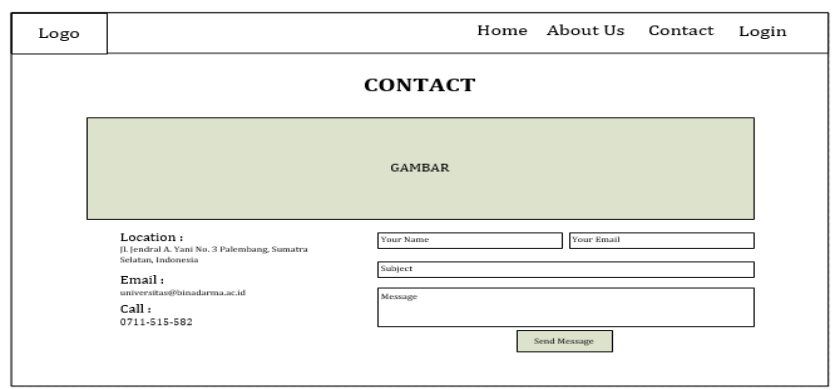

Gambar 4.4.3 Rancangan Halaman Contact 


\section{Journal of Computer and Information Systems Ampera}

Vol. 2, No. 3, September 2021 e-ISSN: 2775-2496

https://journal-computing.org/index.php/journal-cisa/index

\subsubsection{Rancangan Halaman Login}

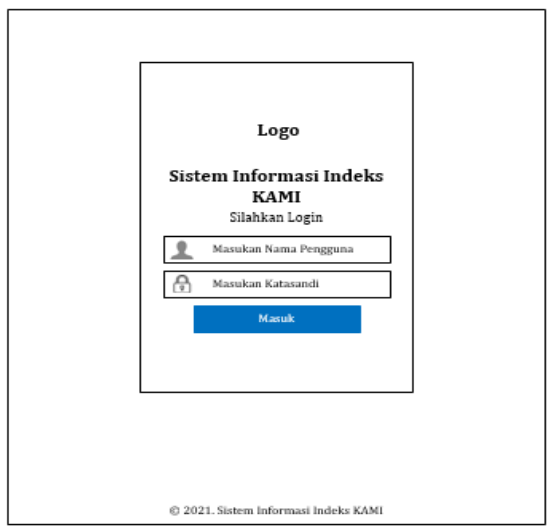

Gambar 4.4.4 Rancangan Halaman Login

\subsubsection{Rancangan Halaman Admin}

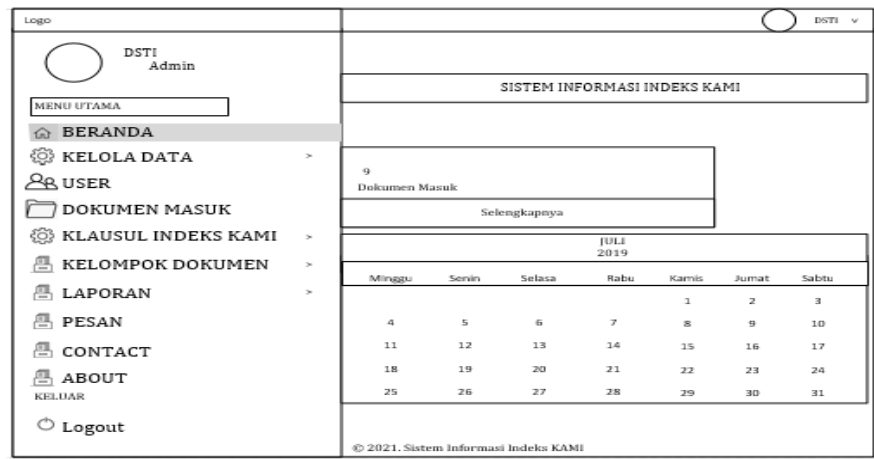

Gambar 4.4.5 Rancangan Halaman Admin 


\section{Journal of Computer and Information Systems Ampera}

Vol. 2, No. 3, September 2021 e-ISSN: 2775-2496

https://journal-computing.org/index.php/journal-cisa/index

\subsubsection{Rancangan Halaman Kelola Data Hardware}

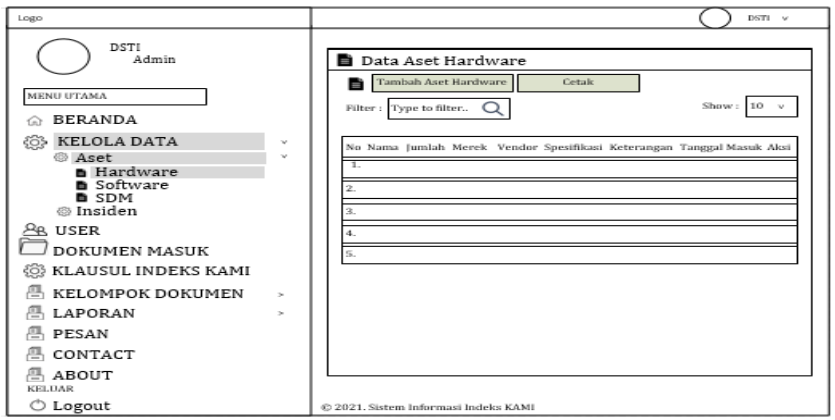

Gambar 4.4.6 Rancangan Halaman Kelola Data Hardware

\subsubsection{Rancangan Halaman Kelola Data Software}

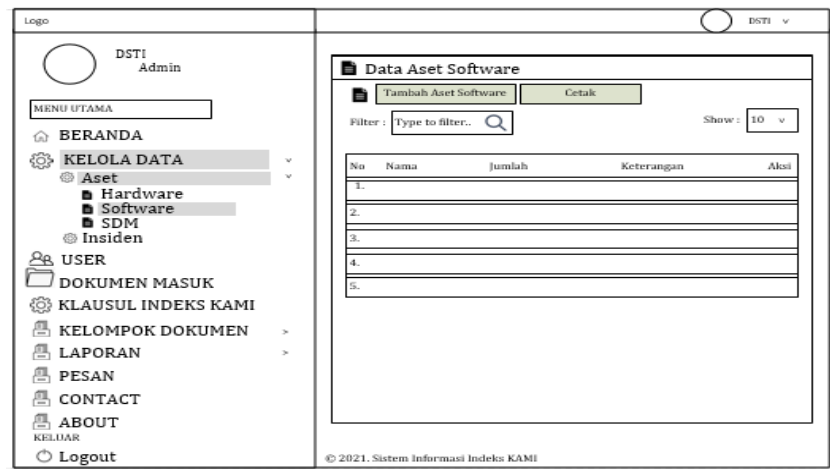

Gambar 4.4.7 Rancangan Halaman Kelola Data Software

\subsubsection{Rancangan Halaman Kelola Data SDM}

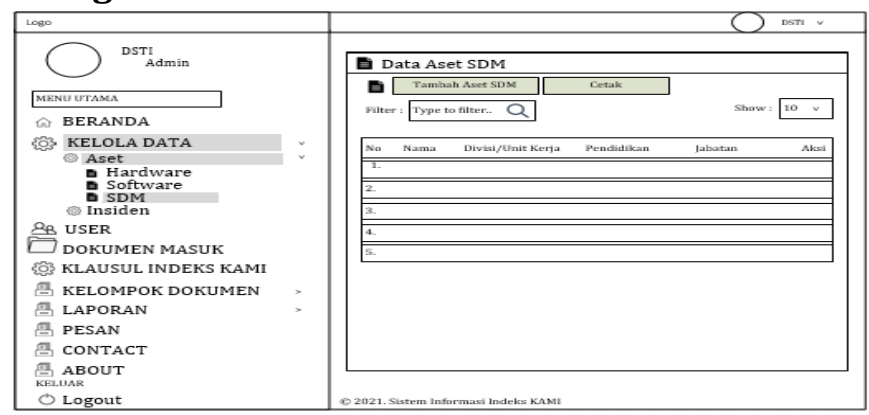

Gambar 4.4.8 Rancangan Halaman Kelola Data SDM 


\section{Journal of Computer and Information Systems Ampera}

Vol. 2, No. 3, September 2021 e-ISSN: 2775-2496

https://journal-computing.org/index.php/journal-cisa/index

\subsubsection{Rancangan Halaman Kelola Data Insiden}

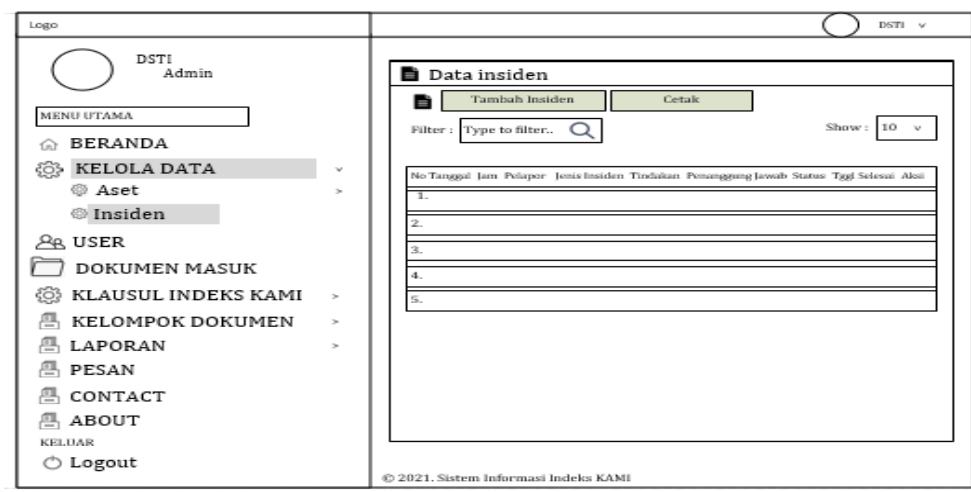

Gambar 4.4.9 Rancangan Halaman Kelola Data Insiden

\subsubsection{Rancangan Halaman User}

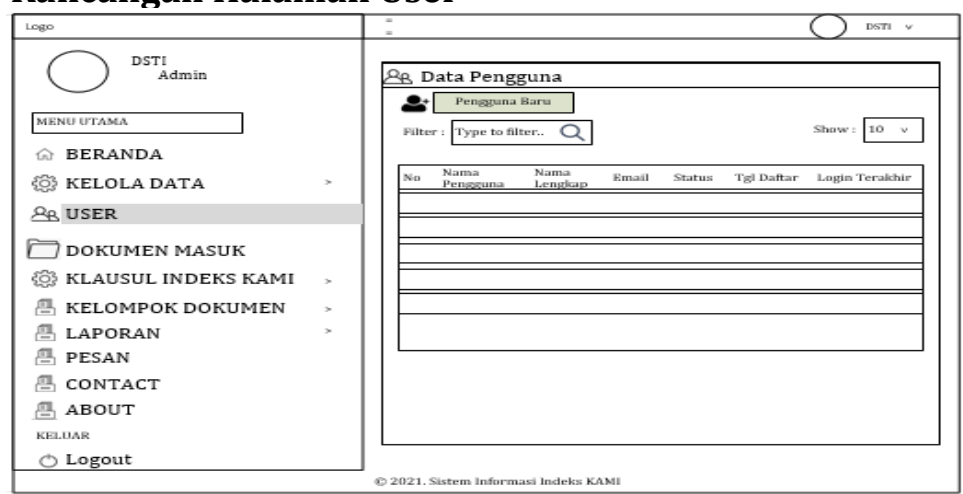

Gambar 4.4.10 Rancangan Halaman User 


\section{Journal of Computer and Information Systems Ampera}

Vol. 2, No. 3, September 2021 e-ISSN: 2775-2496

https://journal-computing.org/index.php/journal-cisa/index

\subsubsection{Rancangan Halaman Tambah User}

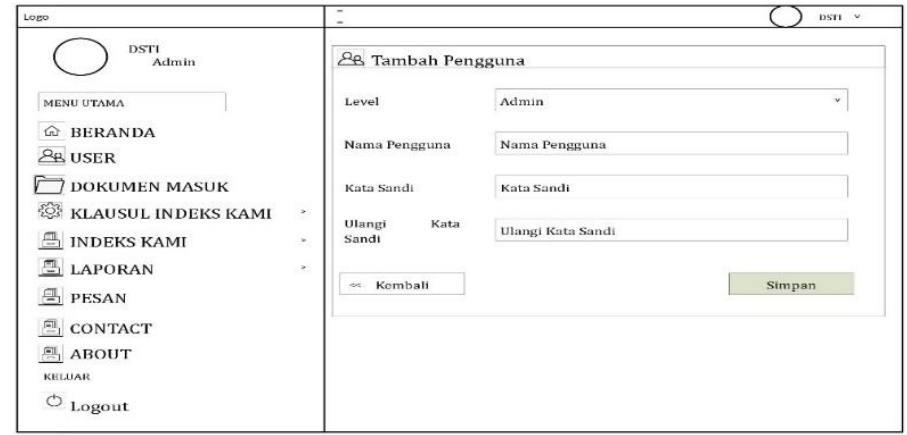

Gambar 4.4.11 Rancangan Tambah Halaman User

\subsubsection{Rancangan Halaman Klausul}

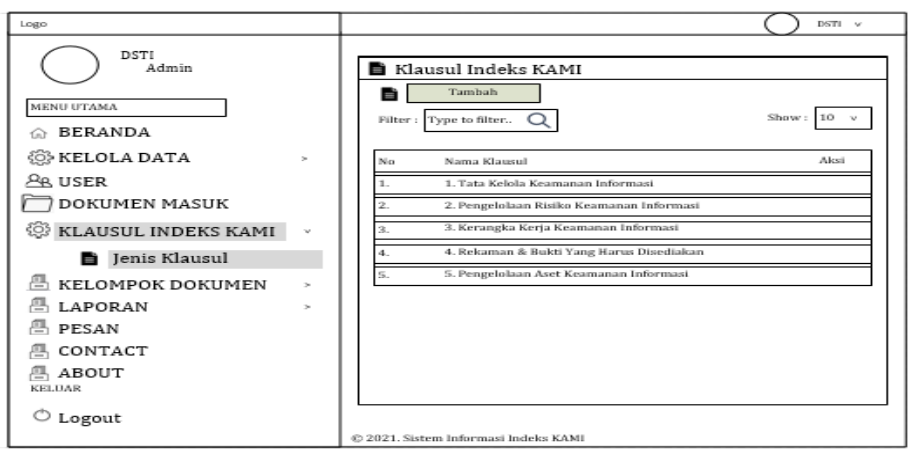

Gambar 4.4.12 Rancangan Halaman Klausul

\subsubsection{Rancangan Halaman Dokumen Masuk}

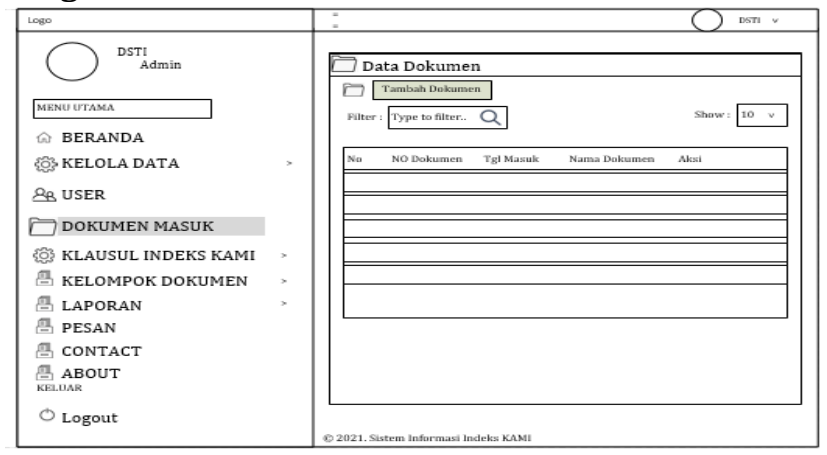

Gambar 4.4.13 Rancangan Halaman Dokumen Masuk 


\section{Journal of Computer and Information Systems Ampera}

Vol. 2, No. 3, September 2021 e-ISSN: 2775-2496

https://journal-computing.org/index.php/journal-cisa/index

\subsubsection{Rancangan Halaman Tambah Dokumen}

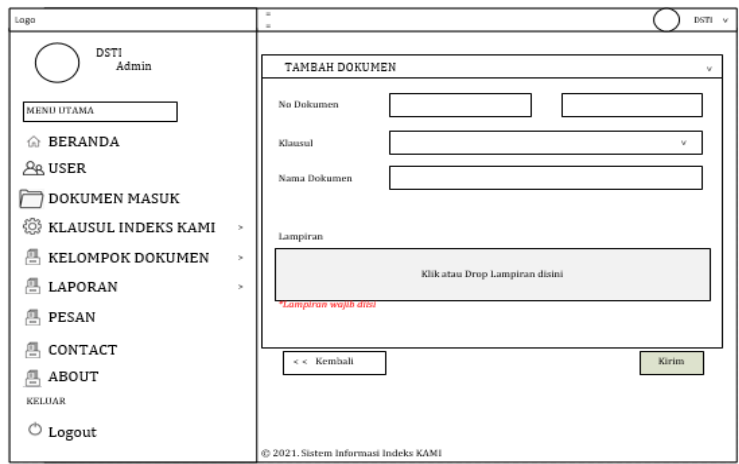

Gambar 4.4.14 Rancangan Halaman Tambah Dokumen

\subsubsection{Rancangan Halaman Update Dokumen}

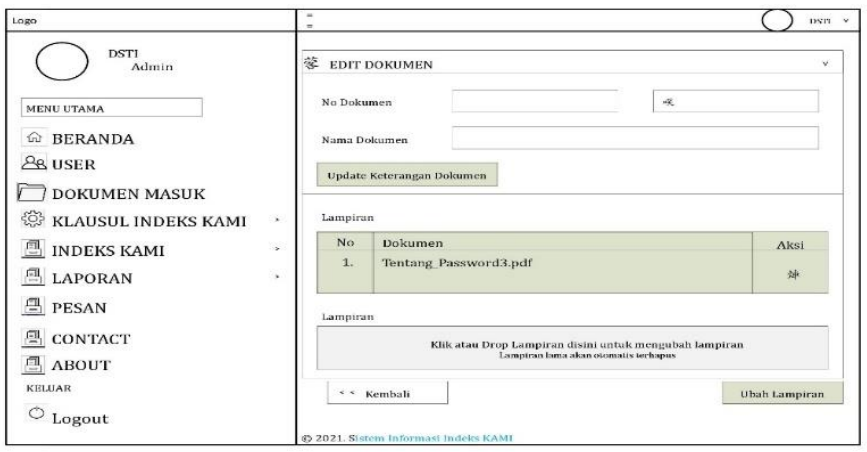

Gambar 4.4.15 Rancangan Halaman Update Dokumen

\subsubsection{Rancangan Halaman Laporan}

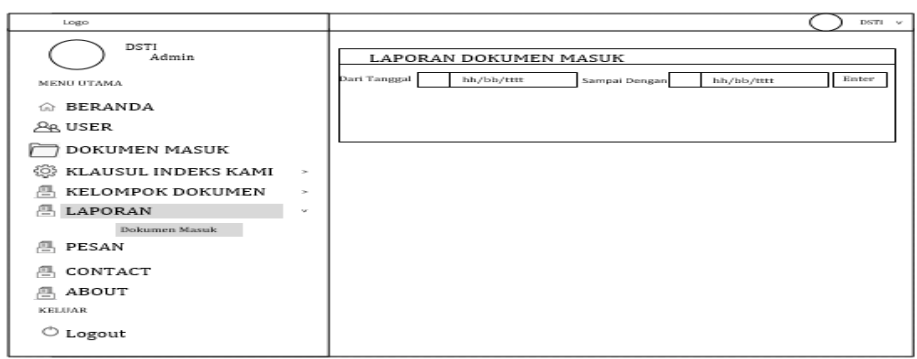

Gambar 4.4.16 Rancangan Halaman Laporan 


\section{Journal of Computer and Information Systems Ampera}

Vol. 2, No. 3, September 2021 e-ISSN: 2775-2496

https://journal-computing.org/index.php/journal-cisa/index

\section{Penutup}

\subsection{Kesimpulan}

Berdasarkan proses yang telang dilakukan dalam perancangan sistem informasi Indeks KAMI berbasis web bagi Universitas Bina Darma maka diambil beberapa kesimpulan yaitu, dengan adanya sistem ini memberikan kemudahan dalam melakukan evaluasi bagi Universitas Bina Darma.

\subsection{Saran}

Penulis menyadari bahwa Perancangan Sistem Informasi Indeks KAMI ini masih memiliki banyak kekurangan, oleh karna itu apabila penelitian ini ingin dilanjutkan ada beberapa mengenai sistem ini yang sebaiknya lebih ditingkatkan, yaitu :

1. Disarankan sistem informasi yang telah dihasilkan dapat dimanfaatkan pada Universitas Bina Darma.

2. Untuk pemeliharaan sistem informasi ini perlu adanya evaluasi secara rutin sehingga dapat dilihat apakah perlu adanya perbaikan dan penyempurnaan kembali atau perlu dikembangankan lagi.

\section{DAFTAR PUSTAKA}

Andita, R., Nurul, P., Rachmatullah, P., Akbar, S., Permata, S., \& Mulyaningsih, S. (2016). Analisis dan Perancangan Sistem Informasi Pelayanan Obat di Apotek Generik. Jurnal Edukasi dan Penelitian Informatika (JEPIN), 2(1). https://doi.org/10.26418/jp.v2i1.15463

Basyarahil, F. A. (n.d.-a). SECURITY MANAGEMENT USING INDEKS KEAMANAN INFORMASI (KAMI) BASED ON ISO/IEC 27001:2013 AT DIREKTORAT PENGEMBANGAN TEKNOLOGI DAN SISTEM INFORMASI (DPTSI) ITS SURABAYA. 393.

Darman. (2019). MEMBANGUN SISTEM INFORMASI SEKOLAH BERBASIS WEB PADA SMA NEGERI 4 RAHA [Preprint]. AgriXiv. https://doi.org/10.31220/osf.io/pwynm 


\section{Journal of Computer and Information Systems Ampera}

Vol. 2, No. 3, September 2021 e-ISSN: 2775-2496

https://journal-computing.org/index.php/journal-cisa/index

Ependi, U. (n.d.). PENGEMBANGAN SISTEM INFORMASI ONLINE MENGGUNAKAN METODE WEB ENGINEERING. 11.

Hadinata, N., \& Udariansyah, D. (n.d.). IMPLEMENTASI METODE WEB ENGINEERING DALAM PERANCANGAN SISTEM INFORMASI PENERIMAAN MAHASISWA BARU DAN TES ONLINE. 12.

Prabowo, F. A. (n.d.). Sistem Informasi Pengolahan Sertifikat Berbasis Web Di Divisi Training SEAMOLEC. 7.

Taufik, A. (2018). Perancangan Sistem Informasi Pelayanan Kesehatan (Studi Kasus: Klinik Nayaka Era Husada Jakarta). Infotech: Journal of Technology Information, 4(1), 23-28. https://doi.org/10.37365/it.v4i1.11

Wahyuono, R. (n.d.). FAKULTAS TEKNOLOGI DAN INFORMATIKA INSTITUT BISNIS DAN INFORMATIKA STIKOM SURABAYA. 89 